\title{
Assessment of National Plant Breeding and Biotechnology Capacity in Africa and Recommendations for Future Capacity Building
}

\author{
E.P. Guimarães ${ }^{1}$ and E. Kueneman ${ }^{2}$ \\ Food and Agriculture Organization of the United Nations, Rome, Italy \\ M.J. Carena ${ }^{3}$ \\ North Dakota State University, Fargo, ND 58105-5051
}

\begin{abstract}
The demands being placed on crop production are increasing, particularly in developing countries. In many instances, the rate of gain in crop yields has dropped while input costs (e.g., fertilizers) have undermined the potential benefits gained from introducing new varieties. This situation is particularly true in Africa. The challenge is to meet increased demands for food from a growing population by developing new varieties and improving agricultural production methods that are sustainable in the long term, with minimal negative consequences for the environment.
\end{abstract}

There is an opportunity to enhance agricultural production by applying the results of research to meet the demands for food security and environmental conservation. We believe that ensuring strong plant breeding programs in national agricultural research systems (NARS) will be essential in ensuring the sustainable use of plant genetic resources for the benefit of mankind.

Our first step was the assessment of the current state of 12 African plant breeding programs and trends in the allocation of resources within NARS. This has been the key to identifying gaps in order to develop strategies to strengthen sustainable use of Plant Genetic Resources for Food and Agriculture (PGRFA) in these programs.

The FAO of the United Nations, in collaboration with the Consultative Group on International Agricultural Research (CGIAR) centers and other stakeholders, is assessing plant breeding and related biotechnology country capacity, as set out in the Global Plan of Action (article 14) of the International Treaty on Plant Genetic Resources for Food and Agriculture (ITPGRFA). As such, FAO is surveying country information and trends in resource allocation for plant breeding and biotechnology, with the aim of raising awareness and evaluating opportunities for investment. This is the first step towards designing national, regional and/or global strategies to strengthen the capacity of national plant breeding programs.

This report concentrates on 12 African countries. In this paper we 1) describe the survey mechanism used by FAO; 2) report on preliminary information gathered on 12 African countries; 3) summarize the recommendations

${ }^{1}$ Cereal and crop breeding. Corresponding author; e-mail Elcio.Guimaraes@ndsu.edu.

${ }^{2}$ Grass land service chief.

${ }^{3}$ Currently, visiting scientist, Food and Agriculture Organization of the United Nations, Rome, Italy. made by an expert group which reviewed the preliminary information; 4) indicate the potential of the information available for planning breeding strategies; and 5) indicate how FAO views the road ahead.

\section{THE SURVEY}

In 2002, a draft questionnaire was designed to gather country information on resource allocation trends in plant breeding and biotechnology related activities. Later in the same year, a group of experts including representatives from CGIAR centers, the public and private sectors, and non-governmental organizations (NGOs), met at FAO, Rome, to discuss what information to obtain and what procedure to use. As a result, a questionnaire was developed. The first part of the survey focuses on organization type, the number of years in the business, and the number of full-time equivalent plant breeders and biotechnologists available on a 5-year basis for each 5-year period starting in 1985 . The second part of the survey requests trend of plant breeding budgets again on a 5 -year basis, the resource allocation per crop, and the resource allocation in germplasm improvement (prebreeding), line development, line evaluation, and in biotechnology. The survey also requests information on number of crosses, number of segregating populations, number of field trials and testing locations as well as the origin of the genetic resources used in the breeding programs. Finally, the survey concentrated on priority breeding environments, potential international support to strengthen national breeding programs, the number of varieties released, and the factors that are most likely to limit the success of plant breeding programs.

The work of gathering the information is assigned to a well-known and respected national plant scientist, preferably working in the area of plant breeding within each country. The survey is sent to all public and private plant breeding programs in the country. The scientist has the responsibility of not only gathering information but also preparing a technical report of the current national plant breeding status.

This paper provides information on 12 countries in eastern and southern Africa (Angola, Kenya, Malawi, Mozambique, Zambia, and Zimbabwe) and western Africa (Cameroon, Ghana, Mali, Niger, Nigeria, and Senegal) and preliminary assessments of needs and opportunities related to plant breeding to ultimately enhance agricultural productivity, food security, and poverty alleviation.

\section{RESULTS OF THE AFRICAN SURVEY}

Among the selected countries, Zimbabwe had the highest percentage increase in number of breeders and biotechnologists (205\%), as it went from 20 in 1985 to 41 in 2001 (Table 1). This country was followed by Mozambique (from 10 to 28 breeders) and Senegal (from three to eight breeders). All other countries had increases smaller than 50\%, except Angola and Malawi, where the number of breeders actually fell during that period. Even though percentage increases are useful indicators of trends, the numbers themselves are more informative in

Table 1. Number of plant breeders and biotechnologists in 1985 and 2001 in 12 African countries and their percentage change. In parentheses there are the numbers of biotechnologists in the respective countries in 2001.

\begin{tabular}{lccc}
\hline Country & $1985^{z}$ & 2001 & Change (\%) \\
\hline Eastern and southern Africa & & & \\
$\quad$ Zimbabwe & 20 & $41(13)^{\mathrm{y}}$ & 205 \\
Mozambique & 10 & $28(1)$ & 180 \\
Kenya & 39 & $52(6)$ & 33 \\
Zambia & 20 & $26(0)$ & 30 \\
Angola & 10 & $7(2)$ & -30 \\
Malawi & 78 & $41(0)$ & -47 \\
Western Africa & & & \\
Senegal & 3 & $8(6)$ & 167 \\
Cameroon & 27 & $38(18)$ & 41 \\
Mali & 30 & $40(5)$ & 33 \\
Nigeria & 42 & $55(16)$ & 31 \\
Ghana & 15 & $19(17)$ & 27 \\
Niger & 11 & $12(0)$ & 9 \\
\hline
\end{tabular}

${ }^{2}$ No biotechnologists were present in 1985 .

${ }^{y}$ Numbers outside parentheses are total numbers of breeders and numbers in parentheses are total numbers of bitoechnologists. 
that they reflect a country's capacity. For example, in 2001, the countries with the highest Kenya with 52 (Table 1).

The use of biotechnological tools did not appear to be an important component of the African countries'breeding strategies in 1985, as no biotechnologists were reported to be working in the selected countries. By 2001, however, the situation had changed dramatically. Among the 12 countries only three did not have any biotechnologists. In addition, countries including Cameroon, Ghana, Nigeria, and Zimbabwe had more than 10 (Table 2). Even though there are fewer reported numbers of breeders were Nigeria with 55 and

biotechnologists working in the eastern and southern African countries than the ones in western Africa, we have evidence that the former region has more biotechnology research and related development currently underway. There are scientists working with tissue culture in the 12 African countries. This technique has been used in cassava, banana, pineapple, yams, sweet potato, and oil palm. Tools such as marker-assisted selection(MAS) and genetic engineering are limited to a few countries; only in Kenya, Nigeria, and Zimbabwe was there use of both technologies indicated. Cameroon, Ghana, and Niger indicated that MAS is being used on cassava and cowpea. Survey results

Table 2. Biotechnology applications in use in 12 African countries in 2001. Data included information collected in the survey and FAO-BioDeC database (http://www.fao.org/biotech/inventory_admin/dep/ default.asp). $\mathrm{TC}=$ tissue culture, $\mathrm{MAS}=$ marker-assisted selection, and $\mathrm{GE}=$ genetic engineering.

\begin{tabular}{lccc}
\hline Country & TC & MAS & GE \\
\hline Eastern and southern Africa & Yes & Yes & Yes \\
Zimbabwe & Yes & No & No \\
Mozambique & Yes & Yes & Yes \\
Kenya & Yes & No & No \\
Zambia & Yes & No & No \\
Angola & Yes & No & No \\
Malawi & & & No \\
Western Africa & Yes & Yes & No \\
Senegal & Yes & No & No \\
Cameroon & Yes & Yes & Yes \\
Mali & Yes & Yes & No \\
Nigeria & Yes & Yes & No \\
Ghana & Yes & & \\
Niger & & & \\
\hline
\end{tabular}

Table 3. Educational level (\%) of plant breeders in 1985 and 2001 in 12 African countries.

\begin{tabular}{|c|c|c|c|c|c|c|}
\hline \multirow[b]{3}{*}{ Country } & \multicolumn{6}{|c|}{ Education level (\%) } \\
\hline & \multicolumn{2}{|c|}{$\mathrm{BSc}$} & \multicolumn{2}{|c|}{$\mathrm{MSc}$} & \multicolumn{2}{|c|}{$\mathrm{PhD}$} \\
\hline & 1985 & 2001 & 1985 & 2001 & 1985 & 2001 \\
\hline \multicolumn{7}{|c|}{ Eastern and southern Africa } \\
\hline Zimbabwe & 75 & 44 & 25 & 50 & 0 & 6 \\
\hline Mozambique & 80 & 54 & 0 & 29 & 20 & 17 \\
\hline Kenya & 50 & 13 & 40 & 48 & 10 & 38 \\
\hline Zambia & 45 & 47 & 40 & 42 & 15 & 11 \\
\hline Angola & 80 & 72 & 20 & 0 & 0 & 28 \\
\hline Malawi & 26 & 29 & 45 & 4 & 29 & 27 \\
\hline \multicolumn{7}{|l|}{ Western Africa } \\
\hline Senegal & 0 & 25 & 100 & 25 & 0 & 50 \\
\hline Cameroon & 37 & 34 & 37 & 32 & 26 & 24 \\
\hline Mali & 47 & 31 & 33 & 42 & 20 & 27 \\
\hline Nigeria & 55 & 7 & 38 & 38 & 7 & 55 \\
\hline Ghana & 33 & 5 & 40 & 37 & 27 & 58 \\
\hline Niger & 18 & 34 & 82 & 25 & 0 & 41 \\
\hline
\end{tabular}

Table 4. Crops with the largest number of full-time equivalent breeders working in 12 African countries in 2001 .

\begin{tabular}{lrccr}
\hline Country (no.) & Maize & Roots and tubers & Grain legume & Other $^{\mathbf{y}}$ \\
\hline Eastern and southern Africa & & & & \\
$\quad$ Zimbabwe (41) & 14.4 & 0.0 & 0.0 & 26.6 \\
Mozambique (28) & 8.7 & 8.7 & 5.6 & 5.0 \\
Kenya (52) & 18.9 & 2.1 & 11.0 & 20.0 \\
Zambia (26) & 9.3 & 2.4 & 0.8 & 13.5 \\
Angola (7) & 2.5 & 1.4 & 1.4 & 1.7 \\
Malawi (41) & 8.2 & 5.7 & 2.1 & 25.0 \\
Western Africa & & & & 5.2 \\
Senegal (8) & 1.0 & 0.5 & 1.3 & 25.1 \\
Cameroon (38) & 4.4 & 6.2 & 0.3 & 37.5 \\
Mali (40) & 0.8 & 1.4 & 0.3 & 36.8 \\
Nigeria (55) & 12.0 & 5.0 & 1.2 & 10.7 \\
Ghana (19) & 1.7 & 4.8 & 1.8 & \\
\hline
\end{tabular}

${ }^{\mathrm{Z}}$ Numbers in parentheses represent full-time equivalent breeders.

${ }^{y}$ Vegetables and fruits: Kenya (3.5); Senegal (4.3), Malawi (6.5), and Nigeria (10.2). Sorghum and millet are important in Zambia (3.0), Kenya (5.0), and Mali (17.4). Fiber crops: Zimbabwe (4.0), Cameroon (5.0), and Mali (9.6). from Nigeria imply that, at some level, genetic engineering is been applied in cassava, banana, and date palm (Table 2). In all cases, however, the impact of biotechnology tools has never been measured.

The educational level of African plant breeders has improved since 1985. Comparing the percentages of scientists with BS degrees across years, there was actually a decrease in almost all countries, except for Zambia, Malawi, Senegal, and Niger. The reason for this change is that scientists have pursued higher level degrees (Table 3). Overall, the number of breeders generally increased, except in Angola and Malawi. Only in Kenya, Senegal, Nigeria, and Ghana has the number of plant breeders with MS and PhD degrees increased dramatically, while in Angola and Mozambique there are more breeders with only BS degrees.

Only a limited number of crops are being widely bred across Africa (Table 4). Maize is the most common of these, followed by roots and tubers, and grain legumes. Other crops receiving country-wide attention include vegetables and fruits (Kenya, Malawi, Nigeria, and Senegal), sorghum and millet (Kenya, Mali, and Zambia), and fibers (Cameroon, Mali, and Zimbabwe).

\section{RECOMMENDATIONS FOR FUTURE PLANT BREEDING CAPACITY BUILDING}

The results of this survey were presented to a group of experts who attended a workshop organized by FAO in February 2005. The African report was presented as an example of the current state of breeding capacity in one region of the world, although the panel's brief was global. The aim was to bring together participants from many regions, representing a variety of backgrounds and possessing the necessary expertise to discuss the problem of the decline support in plant breeding and suggest how this might be solved. After three days of discussions, the group came up with the following recommendations for FAO, NARS, donors, CGIAR centers, and policymakers:

\section{FAO}

- Increase awareness among all stakeholders of the strategic importance of sustainable crop improvement through plant breeding.

- Encourage all stakeholders in plant breeding, in both developing and developed countries, to increase the awareness of its value and impact and apply appropriate biotechnology to development.

- Take note of the momentum that has been created through the Convention on Biological Diversity, the ITPGRFA and the Global Crop Diversity Trust, and establish, in a systematic manner, a platform for strategic thinking for future development of sustainable use of PGRFA, which would necessarily include plant breeding and the application of biotechnology.

- Consider establishing a fund to support sustainable plant breeding, including genetic enhancement, for crops that have not received the due attention of plant breed- 
ers and crop scientists, in countries and for programs requiring support. Capacity building would be a key component.

\section{NARS}

- Improve priority setting, incorporating awareness of markets and consumption chains and trends in scientific and technological innovation.

- Play an increasingly active role in decision making, especially in connection with strengthening of capacity building.

- Adopt a multidisciplinary approach to plant breeding, including biotechnology where appropriate.

- Attempt to develop a solid and stable infrastructural and national financial base to ensure sustainability of crop improvement.

- Seek to develop improved linkages, including those with farmers and the private sector and particularly with the informal seed sector, where possible.

- Increase awareness of the strategic importance of sustainable crop improvement.

- Monitor and evaluate the impacts of IPR/IP on the development and effectiveness of breeding so that adjustments to strategies can be made on an informed basis.

\section{Donors}

- Listen to all parties and promote awareness with a view to supporting plant breeding and its enhancement in developing countries.

- Exert influence in developing strong support base in each country.

- Improve coordination among donors.

- Support networks in order to enhance capacity of national programs, including the use of mechanisms such as that of the Global Plan of Action for PGRFA.

- Support efforts to facilitate merging and integration of conventional and advanced breeding strategies.

- Contribute to initiatives that foster sustained funding and long-term support needed to carry out plant breeding.

\section{CGIAR centers}

- Review survey documentation and advise on interpretation and strategic investments in crop improvement.

- Balance donor demands with the needs of NARS and continue to support plant breeding through research and capacity building in line with the needs of national programs and national program staff.

- Monitor the impact of capacity building efforts with a view to maintaining focused programs.

- Encourage and support cooperation at regional and sub-regional levels, and enhance south-south linkages.

- Coordinate efforts to facilitate merging and integration of conventional and advanced breeding strategies.

- Provide leadership in transfer of tools and technologies to NARS.

\section{Policymakers}

- Recognize the continued importance of agriculture to the national economies of developing nations and to the livelihoods of the rural and urban populations therein.

- Recognize the contribution of plant breeding to improved food security and income generation in developing nations.

- Understand the long-term nature of plant breeding and the need for sustained support to ensure its success.

- Encourage multi-stakeholder participation in decision-making processes that support conservation and use of PGRFA.

- Encourage highly professional debate on plant breeding, relying on specialized representation, in forums such as the ITPGRFA, while stressing its importance in maintaining livelihoods in developing nations.

- Harmonize policies related to the sustainable use of PGRFA including seed systems.

- Examine and understand the linkages between sustainable use and conservation of PGRFA.

- Assist in implementing appropriate forms of rights for the developers and users of plant varieties used in agriculture in developing nations.

- Monitor and evaluate the impacts of IPR/IP on the development and effectiveness of breeding so that adjustments to strategies can be made on an informed basis.

\section{CONCLUSIONS AND WORK AHEAD}

Preliminary data for Africa indicate that local breeding programs are poorly funded, which risks human resource training. In fact, in nearly all countries, there is less financial support today than there was in 1985 . In some cases, the decrease has been more than 10-fold.
The survey of selected countries in Africa indicates that financial resource allocations to plant breeding and related biotechnology are sharply declining. Local plant breeding programs are generally poorly funded, including funds for field trials, staff travel, data analysis, and infrastructure.

The number of breeders (including biotechnologists) have increased in some countries over the last 15 years but current numbers are still below the critical level in most cases in order to make an impact on major crops. Moreover, the educational level of breeders, in general, is not high enough to allow them to carry out efficient breeding programs. Furthermore, while there are crops and crop groups (e.g., maize, sorghum, cowpea, beans, rice, cassava, sweet potato, tomato, onion to name a few) that receive some attention across whole regions, which would allow for the development of regional breeding strategies, there are, however, other crops and crop groups (e.g., local fruits and vegetables) which are more country specific and need to be dealt with at country level.

Preliminary survey results on Africa can be used by different bodies to plan the way ahead. However, it is imperative to stress that the survey is only the first step in the process of strengthening global plant breeding and biotechnology capacity. As its next step, FAO views the organization of workshops to discuss with donors, policymakers, and other national and international authorities how to implement the recommendations of the workshop. National support to breeding and associated biotechnology, must be strengthened while FAO expects donors to pledge support to capacity building and to provide guidance towards the ultimate goal of strengthening global capacity in the use of PGRFA.

FAO intends to carry out this survey in other regions of the world. This data will be synthesized in technical scientific reports as well as in documents for policymakers. A database is being prepared to make the collected information available to the general public through a FAO website.

The work ahead will require a great deal of collaboration between the different bodies involved in research and development around the world. FAO sees its role as bringing about concerted action by these bodies which will lead to the alleviation of hunger and improved food security in the world. 